\title{
DETERMINACIÓN DE MICOTOXINAS POR EL MÉTODO DE ELISA EN SOYA PARA AVES EN PRODUCCIÓN EN LA PROVINCIA DE CHINCHA, AÑO 2016
}

\author{
Agustín Guerrero Canelo ${ }^{* a}$, Juan Parreño Tipian ${ }^{\mathrm{b}}$
}

\begin{abstract}
RESUMEN
Se determinó micotoxinas por ELISA en soya para aves en producción en la provincia de Chincha. El 100 \% (20/20), de muestras de 20 molinos de los distritos (Chincha Alta, Pueblo Nuevo, Grocio Prado, Sunampe y Alto Larán) resultaron positivos a aflatoxina B1 (AFB1), ocratoxina $\mathrm{A}(\mathrm{OA})$ y toxina $\mathrm{T}-2$. Niveles máximos permitidos (NMP) para AFB1 (10 ppb), $\mathrm{OA}(50 \mathrm{ppb})$ y toxina $\mathrm{T}-2(150 \mathrm{ppb})$. OA y toxina $\mathrm{T}-2$, con $20 \%$ y $60 \%$ por encima del NMP. Riesgo de ocratoxicosis aguda por el consumo de soya de molinos (Grocio Prado, Sunampe y Alto Larán) y micotoxicosis aguda por toxina $\mathrm{T}-2$, de los distritos de Chincha, excepto Chincha Alta. Sin embargo, la principal alteración de la salud humana y animal, debido a micotoxina, está relacionada con exposición crónica (inducción de cáncer, toxicidad renal y inmunosupresión $)^{4}$.
\end{abstract}

Palabras clave: Aflatoxina B1, ocratoxina A, toxina T - 2, soya, ELISA.

\section{DETERMINATION OF MYCOTOXINS BY THE ELISA METHOD IN SOYBEANS FOR POULTRY IN PRODUCTION IN THE PROVINCE OF CHINCHA, 2016}

\begin{abstract}
Mycotoxins were determined by ELISA in soybeans for birds in production in the province of Chincha. $100 \%$ (20/20) samples from 20 mills in the districts (Chincha Alta, Pueblo Nuevo, Grocio Prado, Sunampe and Alto Larán) were positive for aflatoxin B1 (AFB1), ochratoxin A (OA) and T toxin - 2. Maximum allowed levels (NMP) for AFB1 (10 ppb), OA (50 ppb) and T-2 toxin (150 ppb). OA and T-2 toxin, with $20 \%$ and $60 \%$ above the NMP. Risk of acute ochratoxicosis due to the consumption of soybean mills (Grocio Prado, Sunampe and Alto Larán) and acute mycotoxicosis by $\mathrm{T}$ - 2 toxin, from the districts of Chincha, except Chincha Alta. However, the main alteration of human and animal health due to mycotoxin is related to chronic exposure (cancer induction, renal toxicity and immunosuppression) ${ }^{4}$.
\end{abstract}

Key words: Aflatoxin B1, Ochratoxin A, T - 2 toxin, soybean, ELISA.

\footnotetext{
a Facultad de Medicina Veterinaria y Zootecnia, Universidad Nacional San Luis Gonzaga de Ica, Prolongación Ayabaca c9, Urbanización San José, Ica, Perú, agustingcanelo@gmail.com.

${ }^{b}$ Facultad de Farmacia y Bioquímica de la Universidad Nacional Mayor de San Marcos.
} 


\section{INTRODUCCIÓN}

El frijol soya es una de las leguminosas más importantes a nivel mundial en términos de producción y comercio, contiene en promedio: $17,5 \%$ de grasa y $37,5 \%$ de proteína cruda ${ }^{1}$. Lo cual la hace una excelente fuente de energía y proteína para dietas animales.

Sin embargo, existen factores como la palatabilidad de los alimentos, la biodisponibilidad de los nutrientes o metabolitos que puedan tener efectos tóxicos para el organismo animal. Según la Organización Mundial de la Salud (OMS, 2015), las enfermedades transmitidas por alimentos (ETAs), son generalmente de carácter infeccioso o tóxico. Entre las toxinas naturales con más riesgos para la salud, abarcan las micotoxinas, las biotoxinas marinas, los glucósidos cianogénicos y las toxinas de las setas venenosas.

Hongos toxigénicos, pueden generar micotoxinas al contaminar principalmente los cultivos de cereales, sus derivados y otros productos de origen vegetal; durante la etapa de campo (fitopatógeno: Fusarium), almacenamiento y procesamiento del alimento (saprofíticos: Aspergillus y Penicillium) $)^{2}$. Aunque se tenga buenas condiciones de almacenaje, la contaminación en el campo no puede eliminarse y la micotoxinas es inevitable.

Las micotoxinas se forman al principio de la fase estacionaria o al final de la fase exponencial del crecimiento del moho; son compuestos policetónicos, de bajo peso molecular, generalmente entre 300 a 400 daltons (metabolitos secundarios), generados de las reacciones de condensación en la que se interrumpe la reducción de los grupos cetónicos en la biosíntesis de los ácidos grasos (metabolitos primarios), utilizados por los mohos como fuentes de energía ${ }^{3}$.

Las micotoxicosis pueden clasificarse como agudas o crónicas. La toxicidad aguda, generalmente, tiene un inicio rápido y una respuesta tóxica (Síndrome de Turquía $\mathrm{X}$, ergotismo humano, estaquibotriotoxicosis), mientras que la toxicidad crónica se caracteriza por una exposición a dosis bajas durante un largo período, lo que resulta en cánceres y otros efectos generalmente irreversibles. Casi con certeza, la principal alteración de la salud humana y animal, debido a micotoxina, está relacionada con la exposición crónica (inducción del cáncer, toxicidad renal y inmunosupresión $)^{4}$.

AFB1, es producida por Aspergilus flavus, en más de $106 \mathrm{~g} / \mathrm{kg}$ de sustratos. El hígado es el principal órgano diana ${ }^{4}$.

AFB1, es altamente estable en medio ácido del tracto digestivo y son absorbidos en el intestino para luego adherirse a sus receptores en el hígado y otros tejidos. Es hidroxilado en el hígado y convertido a AFM1, la que se excreta a través de la leche en animales mamíferos y humanos. Su acción carcinogénica se basa en la biotransformación por el sistema hepático microsomal P450 a AFB1 - 8, 9-epóxido, un intermediario altamente reactivo capaz de unirse a las proteínas, a los ácidos ribonucleico (ARN) y desoxirribonucleico (ADN); formando un compuesto estable con el N7 de los residuos guanil que puede causar mutaciones en el codón 
249 del gen p53 (supresor de tumores). Esta alteración es característica de varios carcinomas, especialmente del carcinoma hepático en el hombre. La AFB1 - 8, 9-epóxido forma uniones covalentes (aductos) con los residuos de guanina del ADN, que se excretan por vía urinaria y pueden utilizarse como biomarcadores de exposición en los grupos de riesgo de cáncer del hígado $^{5}$.

La exposición a las aflatoxinas en la dieta se considera como un importante factor de riesgo para el desarrollo de carcinoma hepatocelular primario, particularmente en individuos ya expuestos a la hepatitis $\mathrm{B}^{4}$. En un estudio de casos y controles con más de 18000 muestras de orina recolectados durante 3,5 años en Shanghai, China, al ser analizadas, dieron como resultados: exposiciones a aflatoxina sólo arrojó un riesgo relativo de alrededor de 2, al antígeno del virus de la hepatitis $\mathrm{B}$, con un riesgo relativo de alrededor de 5 y combinadas (aflatoxina y hepatitis B) produjo un riesgo relativo de alrededor de $60^{6}$. La vacunación contra el virus de la hepatitis B se recomienda como una estrategia más realista y rentable para reducir la incidencia de cáncer hepático que eliminar la aflatoxina de la dieta ${ }^{7}$.

Se considera que la soya es un sustrato pobre para la producción de aflatoxinas, de acuerdo a los siguientes reportes: Estados Unidos (1969), se analizaron 866 muestras de las cosechas de 1964 y 1965, de las cuales sólo el 0,2\% (2/866), contenían 7 y 10 ug/kg de aflatoxinas, respectivamente ${ }^{8}$. Argentina (1991), procesaron 94 muestras durante las cosechas de 1986 y 1987; el 9,6\% (9/94) con trazas - 36 ppb de aflatoxinas ${ }^{9}$.

En estudios in vitro se ha demostrado que, cuando las semillas viables de soya son infectadas por A. flavus, producen la fitoalexina (gliceolina), que disminuye sustancialmente la producción de AFB1, sin afectar el crecimiento del hongo; lo que explicaría de manera parcial el por qué la contaminación con aflatoxinas en soya es tan esporádica ${ }^{10}$.

Las ocratoxinas son micotoxinas producidas por hongos del género Aspergillus, siendo la especie más importante $A$. ochraceus. Otras especies de importancia son $A$. sulfureus, $A$. melleus, Penicillium viridicatum, $P$. commune, entre otras especies. La más conocida es OA, siendo a su vez la más tóxica, posee cloro en su molécula. Se conoce además la ocratoxina $\mathrm{B}$ (sin cloro en su molécula) y ocratoxina $\mathrm{C}$ (con cloro y es un etilester). A nivel molecular interfiere con la síntesis de ADN, ARN y proteínas mediante la inhibición de la enzima fenilalanina - ARNt sintetasa. La LD50 para ratas de 20 a $22 \mathrm{mg} / \mathrm{kg}$, siendo principalmente nefrotóxica y hapatotóxica ${ }^{11}$.

Según estudios realizados en Inglaterra, las ocratoxinas parecen ser las micotoxinas más importantes de la soya y sus subproductos; con 19 - 36 \% y niveles de 50 a 500 ppb de OA han sido reportados (tabla 1). 
Tabla 1. Ocurrencia natural de ocratoxina A en frijol soya y productos de soya (Adaptado de Ministry of Agriculture, Fishenes and Food, 1980)

\begin{tabular}{lcccr}
\hline Sustrato & \multicolumn{3}{c}{ Número de muestras } & Rango \\
\cline { 2 - 4 } & Analizadas & Positivas & $\%$ & $(\mathrm{ppb})$ \\
\hline Frijol soya & 25 & 9 & 36,0 & $50-500$ \\
Harina de soya & 21 & 4 & 19,0 & $50-500$ \\
Productos de soya & 28 & 6 & 21,4 & $50-500$ \\
\hline
\end{tabular}

Niveles de $500 \mathrm{ppb}(0,5 \mathrm{ppm})$ son potencialmente tóxicos para la mayoría de especies susceptibles a esta micotoxina tales como humanos, aves, cerdos y perros ${ }^{12}$.

Se reporta los resultados de 64 muestras de torta de soya durante los años 2007 a 2011, que ingresaron al Perú procedente de Paraguay, Argentina, Brasil y Estados Unidos; siendo positivos a OA, $46 / 64(71,9 \%)$ con \pm D. S. $(1,99 \pm 1,63)$ y con rango mínimo y máximo $(0,02$ $-5,99 \mathrm{ppb})^{13}$; sin embargo, el $100 \%$ de las muestras no sobrepasaron los NMP $(0,250 \mathrm{ppm})$.

Las aves más jóvenes parecen ser más susceptibles a la OA que las aves más viejas ya que los pollos de engorde de tres semanas tienen valores de LD50 más altos que los pollos de un día ${ }^{12}$.

Tricoticenos son sesquiterpenos con un peso molecular entre 250 y 550 dalton; reciben su nombre por poseer el esqueleto tetracíclico (12,13 - epoxitricotehec - 9 - eno), presenta un doble enlace entre los carbonos 9 y 10 y un grupo epóxido entre los carbonos 12 y 13, que confiere a la molécula una gran estabilidad. Conservan su actividad bajo muy diferentes condiciones ambientales, incluyendo temperaturas de hasta $120^{\circ} \mathrm{C}$. Según su estructura y especie productora, se dividen en cuatro grupos, A, B, C y D. Grupo A, producidos por Fusarium tricinactun, F. sporotrichioides, F. poe y F. equiseti; presenta un grupo funcional no acetónico en el carbono 8 y entre sus miembros se incluyen las toxinas T -2 y HT -2 y el diacetoxiscirpenol (DAS) ${ }^{14}$.

Los tricotecenos inhiben la síntesis proteica y va seguida de una interrupción secundaria de la síntesis del AND y ARN ${ }^{12}$.

Fusarium sporotrichioides inoculado en soya produjeron Toxina T -2 y HT -2 que se evidencia en la tabla $2^{3}$. 
Tabla 2. Producción de micotoxinas de Fusarium sporotrichioides en soya (Adaptado de Richardson et al., 1985)

\begin{tabular}{|lccc|}
\hline \multicolumn{1}{|c}{ Soya } & $\begin{array}{c}\text { Humedad } \\
(\%)\end{array}$ & $\begin{array}{c}\text { T }-2 \\
(\mathrm{ppm})\end{array}$ & $\begin{array}{c}\text { HT }-2 \\
(\mathrm{ppm})\end{array}$ \\
\hline Frijol entero & 33 & 32 & 49 \\
& 50 & 37 & 80 \\
Frijol partido & 33 & 17 & 109 \\
& 50 & 71 & 111 \\
& 50 & 17 & 71 \\
Torta & 60 & 15 & 46 \\
& 33 & 103 & 285 \\
& 50 & 110 & 284 \\
& 60 & 92 & 439 \\
\hline
\end{tabular}

Se analizaron los resultados de 144 muestras de torta de soya durante los años 2007 a 2011, que ingresaron al Perú peocedente de Paraguay, Argentina, Brasil y Estados Unidos; siendo positivos a toxina $\mathrm{T}-2,128 / 144(88,89 \%)$ con $\pm \mathrm{D}$. S. $(12,96 \pm 9,97)$ y con rango minimo y máximo $(0,08-47,33 \mathrm{ppb}) 13$; sin embargo el $100 \%$ de las muestras no sobrepasaron los $\operatorname{NMP}(0,250 \mathrm{ppm})$.

Los tricotecenos, producen problemas agudos a nivel del tracto gastrointestinal, degeneración de la médula ósea y una inhibición muy significativa del sistema inmunitario. Hay hemorragias en la mucosa epitelial del estómago e intestino con una destrucción de los tejidos hematopoyéticos. Pueden surgir lesiones graves en la molleja de las aves. Las típicas lesiones orales en las aves consiste en una proliferación de placas blanco amarillentas caseosas en la parte inferior y superior del pico, mucosa del paladar, boca y lengua ${ }^{12}$.

Intoxicaciones crónicas con toxina $\mathrm{T}-2$, reduce el consumo de alimento y ganancia de peso, lesiones orales, necrosis de los tejidos linfoides, hematopoyéticos y mucosa oral, con eventuales trastornos nerviosos (posición anormal de las alas, reducción de reflejos), emplume anormal y reducción del espesor de la cáscara de los huevos. En ponedoras, las lesiones orales se producen en aproximadamente el $50 \%$ de los lotes, cuando se alimenta con alimento conteniendo $2 \mathrm{ppm}$. En pollos de engorde se producen lesiones orales a partir de 1 ppm. Las aves presentan reducción del consumo de alimento, retardo en el crecimiento, alteraciones en el cuadro sanguíneo y neurotoxicidad ${ }^{3}$.

Toxina $\mathrm{T}-2$, presenta alta toxicidad para macrófagos de pollos, inhibiendo su capacidad fagocitaria. También induce la formación de peróxidos a partir de los lípidos, acarreando la disminución de la concentración de vitamina $\mathrm{E}$ en las aves ${ }^{3}$. 
Las micotoxinas son consideradas como un contaminante inevitable de los alimentos por la Administracion de Drogas y Alimentos (FDA) de los Estados Unidos. La Organización Mundial de la Alimentación y Agricultura (FAO), en el año 1996, estimó que más del $25 \%$ de los cultivos del mundo estaban contaminados con micotoxinas. Expertos consideran a las micotoxinas como uno de los más importantes factores de riesgo de contaminantes alimenticios crónicos, por encima de los contaminantes sintéticos, plantas tóxicas, aditivos alimentarios o residuos de plaguicidas.

Numerosos autores coinciden que la principal estrategia para evitar las micotoxinas en los alimentos es la prevención, por lo que se debe implantar un sistema integrado basado en el empleo de especies vegetales resistentes, gestión de buenas prácticas agrícolas (BPA) y buenas prácticas de procesado o manufacturación (BPM), análisis de peligros y puntos críticos de control (APPCC) en las fases de producción, desde el campo hasta el consumidor final, empleo de fungicidas y descontaminación.

La producción avícola, que incluye la producción de pollos, gallinas, pavos y patos, llegó a registrar 1'202 614 TM durante el año 2013; 2,7 \% más respecto del año 2012, según estadísticas del Ministerio de Agricultura y Riego (Minagri). La especie pollo es un poco más del $90 \%$ de la población avícola y representa el $53 \%$ del consumo total de carnes en el Perú, seguida del pescado $(31 \%)$, vacuno $(8 \%)$, porcino $(6 \%)$ y ovino $(2 \%)$, calculado en base a cifras de los ministerios de Agricultura y Riego (Minagri) y de la Producción (Produce). Lo anterior está asociado al alto consumo per cápita de carne de pollo en el país, que en el 2013 alcanzó 39 kilogramos. El consumo per cápita de pollo en el Perú se encuentra entre los más altos en la región, después de Brasil (58 kilos) y Argentina (40), superando a Bolivia (35), Chile (32) y Colombia (23), consumos calculados en base a cifras de la Organización de las Naciones Unidas para la Alimentación y la Agricultura (FAO).

Las principales zonas productoras avícolas en el 2013 fueron Lima (53\%), La Libertad (18 \%), Arequipa (9\%) e Ica (5\%), según estadísticas del Minagri.

Por la importancia de la producción avícola en nuestro país, es necesario conocer los niveles de micotoxinas que ingieren con el alimento, para tomar medidas preventivas y eliminarlas o neutralizarlas, previniendo problemas en salud animal y salud pública.

En el presente estudio se ha realizado un screening para identificar y cuantificar las principales micotoxinas que contaminan a la soya (AFB1, OA y toxina $T-2$ ), mediante el método ELISA competitivo directo, adoptadas en seguridad alimentaria, reduciendo el costo y el tiempo empleado. ELISA, utiliza un conjugado (micotoxina marcados con enzima, generalmente la peroxidasa, también la fosfatasa alcalina y $\beta$-galactosidasa), la cual compite con la micotoxina presente en la muestra en estudio por los mismos sitios de enlace presentes en el anticuerpo inmovilizado en la superficie sólida. Debido a que la concentración de conjugado y anticuerpo son constantes, la intensidad del color es inversamente proporcional a la concentración de micotoxina. 


\section{PARTE EXPERIMENTAL}

\section{Tipo y diseño de investigación}

Descriptivo, prospectivo, de corte transversal, observacional y no experimental; empleándose 20 muestras para determinar los valores de micotoxinas por el método de ELISA competitivo directo en soya para aves en producción en la provincia de Chincha.

\section{Unidad de análisis}

Extracto de soya.

\section{Población de estudio}

Soya de 20 molinos de cinco distritos (Alto Larán, Grocio Prado, Sunampe, Chincha Alta y Pueblo Nuevo) de la provincia de Chincha del departamento de Ica.

\section{Tamaño de la muestra}

Para el estudio se tomó 20 muestras, una por cada molino, según la tabla 3.

Tabla 3. Número de muestra, según los molinos de los distritos de la provincia de Chincha.

\begin{tabular}{|lccc|}
\hline Distrito & $\mathbf{N}^{\circ}$ de molinos & $\mathbf{N}^{\mathbf{0}}$ de muestra & Porcentaje \\
\hline Alto Larán & 6 & 6 & 30 \\
Grocio Prado & 5 & 5 & 25 \\
Sunampe & 4 & 4 & 20 \\
Chincha Alta & 2 & 2 & 10 \\
Pueblo Nuevo & 3 & 3 & 15 \\
\hline Total & $\mathbf{2 0}$ & $\mathbf{2 0}$ & $\mathbf{1 0 0}$ \\
\hline
\end{tabular}

\section{Selección de la muestra}

- Se seleccionó un saco de soya de cada molino.

- De cada saco se recolectó la muestra de soya de 5 puntos (4 de los extremos y 1 del centro), a través de un calador de bolsa, considerando que la distribución de las micotoxinas es heterogenéa.

- $\quad$ Se colectó $1 \mathrm{~kg}$ de muestra de soya.

\section{Preparación de la muestra}

Se trituró la muestra de soya hasta obtener partículas finas similar al café instantáneo fino, mediante un molino eléctrico.

\section{Extracción de AFB1:}

- $\quad$ Se mezcló 25 gramos de la muestra triturada con $125 \mathrm{~mL}$. de metanol al 70 \% y se agitó vigorosamente durante tres minutos, se mantuvó en reposo durante tres minutos. 
- $5 \mathrm{~mL}$. del sobrenadante se filtró a través de una jeringa de $10 \mathrm{~mL}$. descartable con filtro de algodón.

- El filtrado (extracto de soya) se recepcionó en viales y se conservó en refrigeración a $4^{\circ} \mathrm{C}$. para ser analizado.

\section{Extracción de OA:}

- 25 gramos de la muestra se mezcló con $100 \mathrm{~mL}$. de metanol al 50 \% y se agitó vigorosamente durante tres minutos, se mantuvó en reposo durante tres minutos.

- $\quad 5 \mathrm{~mL}$. del sobrenadante se filtró a través de una jeringa de $10 \mathrm{~mL}$. descartable con filtro de algodón.

- $\quad$ El extracto de soya se recepcionó en viales.

- $\quad 1 \mathrm{~mL}$. del extracto de soya se diluyó con $1 \mathrm{~mL}$. de metanol al 50 \% y se conservó en refrigeración a $4^{\circ} \mathrm{C}$ para ser analizado.

\section{Extracción de toxina $T$ - 2:}

- Se mezcló 25 gramos de la muestra con $125 \mathrm{~mL}$. de metanol al 70 \% y se agitó vigorosamente durante tres minutos, se mantuvó en reposo durante tres minutos.

- $\quad 5 \mathrm{~mL}$. del sobrenadante se filtró a través de una jeringa de $10 \mathrm{~mL}$. descartable con filtro de algodón.

- $\quad 1 \mathrm{~mL}$. del extracto de soya se diluyó con $1 \mathrm{~mL}$. de agua destilada y se conservó en refrigeración a $4^{\circ} \mathrm{C}$ para ser analizado.

ELISA competitivo directo con kits comerciales (Veratox ${ }^{\circledR}$ HS para aflatoxina, toxina T - 2 y ocratoxina; Neogen ${ }^{\circledR}$ corporation).

Procedimiento, según las recomendaciones del fabricante:

- Temperar los reactivos de 18 a $30^{\circ} \mathrm{C}$ antes de ser utilizado.

- Ubicar en los soportes de pocillos, cinco pocillos de mezclado con la marca roja para los controles de micotoxinas y 20 pocillos para las muestras (M).

\section{Detección y cuantificación de AFB1:}

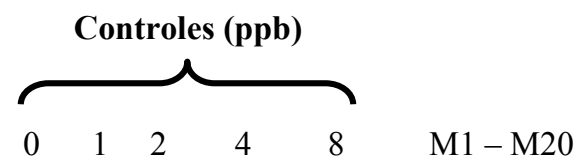

- Los reactivos se agitaron suavemente con movimi $\neg$ entos circulares sobre la mesa de trabajo.

- Colocar 100 uL. de conjugado en cada pocillo de mezclado.

- $\quad$ Adicionar $100 \mathrm{uL}$. de los controles y muestras.

- Mezclar los pocillos succionando y expulsando con una pipeta multicanal de 12 canales durante tres veces.

- Transferir $100 \mathrm{uL}$. a los pocillos recubiertos con anticuerpos.

- Mezclar deslizando el soporte de micropocillos para adelante y para atrás sobre una superficie plana durante 10 a 20 segundos sin salpicar los reactivos. 
- Incubar durante 10 minutos a temperatura ambiente de 18 a $30^{\circ} \mathrm{C}$.

- Extaer el contenido de los pocillos sacudiéndolos. Llenar los pocillos con agua destilada y luego vaciarlos (repetir por cinco veces). Invertir los pocillos y golpearlo suavemente sobre papel toalla hasta retirar el líquido remanente.

- Verter $100 \mathrm{uL}$. de sustrato en los pocillos.

- Mezclar deslizando el soporte de micropocillos para adelante y para atrás sobre una superficie plana durante 10 a 20 segundos sin salpicar los reactivos.

- Incubar durante 10 minutos a temperatura ambiente.

- Adicionar $100 \mathrm{uL}$. de la solución de Red Stop en cada pocillo.

- Mezclar deslizando el soporte de micropocillos para adelante y para atrás sobre una superficie plana durante 10 a 20 segundos sin salpicar los reactivos.

\section{Detección y cuantificación de OA:}

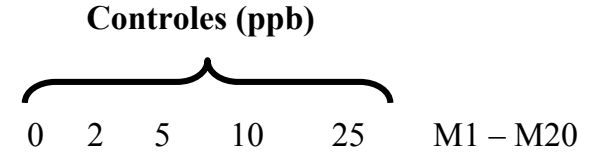

- Los reactivos se agitaron suavemente con movimi $\neg$ entos circulares sobre la mesa de trabajo.

- Colocar $100 \mathrm{uL}$. de conjugado en cada pocillo de mezclado.

- Adicionar $100 \mathrm{uL}$. de los controles y muestras.

- Mezclar los pocillos succionando y expulsando con una pipeta multicanal de 12 canales durante tres veces.

- Transferir $100 \mathrm{uL}$. a los pocillos recubiertos con anticuerpos.

- Mezclar deslizando el soporte de micropocillos para adelante y para atrás sobre una superficie plana durante 10 a 20 segundos sin salpicar los reactivos.

- Incubar durante 10 minutos a temperatura ambiente de 18 a $30^{\circ} \mathrm{C}$.

- Extaer el contenido de los pocillos sacudiéndolos. Llenar los pocillos con agua destilada y luego vaciarlos (repetir por cinco veces). Invertir los pocillos y golpearlo suavemente sobre papel toalla hasta retirar el líquido remanente.

- Verter $100 \mathrm{uL}$. de sustrato en los pocillos.

- Mezclar deslizando el soporte de micropocillos para adelante y para atrás sobre una superficie plana durante 10 a 20 segundos sin salpicar los reactivos.

- Incubar durante 10 minutos a temperatura ambiente.

- Adicionar 100 uL. de la solución de Red Stop en cada pocillo.

- Mezclar deslizando el soporte de micropocillos para adelante y para atrás sobre una superficie plana durante 10 a 20 segundos sin salpicar los reactivos. 


\section{Detección y cuantificación de OA:}

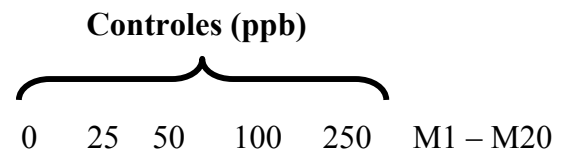

- Los reactivos se agitaron suavemente con movimientos circulares sobre la mesa de trabajo.

- Colocar $100 \mathrm{uL}$. de conjugado en cada pocillo de mezclado.

- $\quad$ Adicionar $100 \mathrm{uL}$. de los controles y muestras.

- Mezclar los pocillos succionando y expulsando con una pipeta multicanal de 12 canales durante tres veces.

- Transferir $100 \mathrm{uL}$. a los pocillos recubiertos con anticuerpos.

- Mezclar deslizando el soporte de micropocillos para adelante y para atrás sobre una superficie plana durante 10 a 20 segundos sin salpicar los reactivos.

- Incubar durante cinco minutos a temperatura ambiente de 18 a $30^{\circ} \mathrm{C}$.

- Extaer el contenido de los pocillos sacudiéndolos. Llenar los pocillos con agua destilada y luego vaciarlos (repetir por cinco veces). Invertir los pocillos y golpearlo suavemente sobre papel toalla hasta retirar el líquido remanente.

- Verter $100 \mathrm{uL}$. de sustrato en los pocillos.

- Mezclar deslizando el soporte de micropocillos para adelante y para atrás sobre una superficie plana durante 10 a 20 segundos sin salpicar los reactivos.

- Incubar durante cinco minutos a temperatura ambiente.

- Adicionar 100 uL. de la solución Red Stop en cada pocillo.

- Mezclar deslizando el soporte de micropocillos para adelante y para atrás sobre una superficie plana durante 10 a 20 segundos sin salpicar los reactivos.

\section{Lectura:}

- Limpiar la base de los micropocillos con una toalla o paño seco.

- Eliminar las burbujas de aire (para no afectar el resultado de los análisis)

- Leer la densidad óptica de cada celdilla, antes de los 20 minutos después de la adición de la solución Red Stop en el lector Biotek ELX800GIDX con filtro de $650 \mathrm{~nm}$.

\section{Técnica de recolección de datos:}

Los valores de micotoxinas se obtuvó con el lector de ELISA. Se determinó la densidad óptica de las muestras, se procesaron en el programa Neogen y se obtuvó los niveles de absorbancia transfiriéndose a ppb $(\mu \mathrm{g} / \mathrm{kg})$.

\section{Estándares}

En la tabla 5 se indican los NMP para la soya. 
Tabla 4. Niveles máximos permitidos de micotoxinas para la soya.

\begin{tabular}{lc} 
Micotoxinas & NMP (ppb) \\
\hline AFB1 & 10 \\
Ocratoxina A & 50 \\
Toxina T -2 & 150 \\
\hline Fuente. Gimeno $(2010)^{15}$. &
\end{tabular}

\section{RESULTADOS Y DISCUSIÓN}

Tabla 5. Niveles de AFB1 en soya, según distritos de Chincha Alta.

\begin{tabular}{llcccccc}
\hline Distritos & $\begin{array}{c}\text { Muestras } \\
\text { analizadas }\end{array}$ & \multicolumn{2}{c}{ Frecuencia } & & \multicolumn{2}{c}{ ppb (ug/kg) } & \multicolumn{2}{c}{$\begin{array}{c}\text { NMP (\%) } \\
\text { positivas }\end{array}$} & relativa & Media & Rango & Mayor & Menor \\
\hline Chincha Alta & 2 & 2 & 100,00 & 1,400 & $1,30-1,50$ & 00,00 & 100,00 \\
Pueblo Nuevo & 3 & 3 & 100,00 & 1,800 & $1,50-2,00$ & 00,00 & 100,00 \\
Grocio Prado & 5 & 5 & 100,00 & 1,860 & $1,20-2,40$ & 00,00 & 100,00 \\
Sunampe & 4 & 4 & 100,00 & 2,100 & $1,50-2,40$ & 00,00 & 100,00 \\
Alto Larán & 6 & 6 & 100,00 & 1,767 & $1,00-3,40$ & 00,00 & 100,00 \\
\hline
\end{tabular}

Niveles máximos permitidos (NMP): AFB1= 10 ppb (Gimeno, 2010).

Tabla 6. Niveles de OA en soya, según distritos de Chincha Alta.

\begin{tabular}{lcccccccc}
\hline Distritos & $\begin{array}{c}\text { Muestras } \\
\text { analizadas }\end{array}$ & \multicolumn{2}{c}{ Frecuencia } & & \multicolumn{2}{c}{ ppb (ug/kg) } & \multicolumn{2}{c}{ NMP (\%) } \\
\hline Chincha Alta & 2 & 2 & 100,00 & 31,050 & $17,60-44,50$ & 00,00 & 100,00 \\
Pueblo Nuevo & 3 & 3 & 100,00 & 34,670 & $21,80-47,20$ & 00,00 & 100,00 \\
Grocio Prado & 5 & 5 & 100,00 & 43,000 & $17,40-80,90$ & 20,00 & 80,00 \\
Sunampe & 4 & 4 & 100,00 & 36,050 & $16,90-55,30$ & 25,00 & 75,00 \\
Alto Larán & 6 & 6 & 100,00 & 34,083 & $03,30-78,00$ & 33,33 & 67,67 \\
\hline
\end{tabular}

Niveles máximos permitidos (NMP): OA $=50$ ppb (Gimeno, 2010). 
Tabla 7. Niveles de toxina $T-2$ en soya, según distritos de Chincha Alta.

\begin{tabular}{lcccccccc}
\hline Distritos & $\begin{array}{r}\text { Muestras } \\
\text { analizadas }\end{array}$ & \multicolumn{2}{c}{$\begin{array}{c}\text { Frecuencia } \\
\text { pos. }\end{array}$} & \multicolumn{2}{c}{ relativa } & Media & Rag/kg) & \multicolumn{2}{c}{ NMP (\%) } \\
\hline Chincha Alta & 2 & 2 & 100,00 & 120,950 & $120,00-121,90$ & 00,00 & 100,00 \\
Pueblo Nuevo & 3 & 3 & 100,00 & 181,370 & $149,80-224,50$ & 67,67 & 33,33 \\
Grocio Prado & 5 & 5 & 100,00 & 169,500 & $142,20-219,60$ & 60,00 & 40,00 \\
Sunampe & 4 & 4 & 100,00 & 194,850 & $125,70-303,50$ & 50,00 & 50,00 \\
Alto Larán & 6 & 6 & 100,00 & 181,033 & $146,70-241,30$ & 83,33 & 16,67 \\
\hline
\end{tabular}

Niveles máximos permitidos (NMP): Toxina $\mathrm{T}-2=150 \mathrm{ppb}$ (Gimeno, 2010).

El $100 \%$ (20/20) de las muestras de soyas de los distritos de Chincha, considerados para el presente estudio (Chincha Alta, Pueblo Nuevo, Grocio Prado, Sunampe y Alto Larán), resultaron positivos a AFB1, con promedios y rangos de ( $\square=1,825 \mathrm{ppb} ; 1,0-3,4 \mathrm{ppb}$ ); sin embargo, el $100 \%$ no sobrepasaron el NMP (10 ppb). Cuyos resultados superan los resultados obtenidos en Argentina, 9,57 \% (9/94), de trazas - 36 ppb $^{9}$; y Estados Unidos, 0,23 \%, de 7 - 10 $\mathrm{ppb}^{8}$. Sin embargo estos, con mayores niveles de AFB1.

Los bajos niveles de AFB1, en las diferentes partes del mundo, se sustenta en que las semillas de soya viables producen gliceolina cuando son infectadas por A. flavus, disminuyendo sustancialnmente la producción de $\mathrm{AFB} 1^{10}$.

En humanos, la exposición a las aflatoxinas en la dieta, se considera como un factor de riesgo para el desarrollo de carcinoma hepatocelular primario, particularmente en individuos ya expuestos al virus de la hepatitis $\mathrm{B}^{4}$, con un riesgo relativo de 60 en comparación de exposición sólo a aflatoxina de 2 y exposición sólo al virus de hepatitis B alrededor de $5^{6}$; por lo que se recomienda la vacunación contra el virus de la hepatitis B para reducir la incidencia de cáncer hepático ${ }^{7}$.

Con respecto a los resultados de OA del presente estudio, el $100 \%(20 / 20)$ de las muestras de soyas, resultaron positivas, $(\square=36,49 \mathrm{ppb} ; 3,3-80,9 \mathrm{ppb})$ y el $20 \%$ de las muestras con valores por encima de los NMP (50 ppb); =70,025; 55,3 - 80,9 ppb. Cuyos resultados de muestras positivas, superiores a los reportados de Inglaterra, de $19-36 \%$, sin embargo, estos con mayores niveles de 50 a $500 \mathrm{ppb}^{12}$.

El $20 \%$ de las muestras que sobrepasaron los NMP, podrían ser un factor de riesgo para ocratoxicosis aguda; sin embargo el $80 \%$, serían responsables de ocratoxicosis crónica, siendo principalmente nefrotóxica, hepatotóxica ${ }^{11}$.

Referente a la toxina $\mathrm{T}-2$, el $100 \%(20 / 20)$ de las muestras de soyas, resultaron positivas $(\square=174,97 \mathrm{ppb} ; 120,0-303,5 \mathrm{ppb})$ y el $60 \%$ de muestras con valores por encima de los NMP (150 ppb); $\square=200,075 ; 154,5-241,3)$. Con resultados de muestras positivas 
superiores a los resultados de los registros de torta de soya, que ingresaron al Perú entre los años (2007 - 2011), procedente de Paraguay, Argentina, Brasil y Estados Unidos: 88,9 \%, = 12,$96 ; 0,08-47,3313$ y el $100 \%$ no sobrepasaron los $\operatorname{NMP}(0,250 \mathrm{ppm})$.

En ponedoras, las lesiones orales se producen aproximadamente en el $50 \%$ de los lotes, cuando se alimenta con alimento con $2 \mathrm{ppm}$ de toxina $\mathrm{T}-2$. En pollos de engorde se producen lesiones orales a partir de $1 \mathrm{ppm}$. Se reduce el consumo de alimento, retardo en el crecimiento, alteraciones en el cuadro sanguíneo y neurotoxicidad. Presenta alta toxicidad para macrófagos, inhibiendo su capacidad fagocitaria. Induce la formación de peróxidos a partir de los lípidos, disminuyendo la concentración de vitamina $\mathrm{E}^{3}$.

\section{CONCLUSIONES}

1. En la provincia de Chincha se identificó en las muestras de soya, por el método de ELISA competitivo directo, que el $100 \%$ resultaron positivas para micotoxinas y el $26,67 \%$ con niveles superiores a los NMP.

2. Los valores de AFB1 fluctúan entre 1,00-3,40 ppb. Los cuales no sobrepasan los NMP de $10 \mathrm{ppb}$. Por lo tanto, la AFB1 no es un factor de riesgo para aflatoxicosis aguda por el consumo de soya, procedente de los molinos de los distritos de Chincha, considerados en el presente estudio (Chincha Alta, Pueblo Nuevo, Grocio Prado, Sunampe y Alto Larán),

3. Los valores para OA fluctúan entre 0,3-80,90 ppb. El $20 \%$ de las muestras sobrepasan los NMP de $50 \mathrm{ppb}$. OA es un factor de riesgo para ocratoxicosis aguda por el consumo de soya en la dieta de los animales, de los distritos de Grocio Prado, Sunampe y Alto Larán.

4. Los valores de toxina T - 2, fluctúan entre 120,950 - 303,50 ppb. El $60 \%$ de las muestras sobrepasan los NMP de $150 \mathrm{ppb}$. Siendo la de mayor magnitud en el presente estudio, sólo el distrito de Chincha Alta, obtuvieron resultados por debajo de los NMP; pudiendo ser un factor de riesgo para micotoxicosis aviar aguda por el consumo de soya procedente de los molinos de los distritos de Pueblo Nuevo, Grocio Prado, Sunampe y Alto Larán.

5. Sin embargo la principal alteración de la salud humana y animal, debido a micotoxina, está relacionada con exposición crónica (inducción de cáncer, toxicidad renal y inmunosupresión $)^{4}$.

\section{AGRADECIMIENTO}

- $\quad$ Al Dr. Juan Manuel Parreño Tipian, por su asesoría en el presente estudio.

- A la Facultad de Medicina Veterinaria y Zootecnia de la Universidad Nacional San Luis Gonzaga de Ica, por las instalaciones para llevar a cabo los procesamientos y los análisis de las muestra. 


\section{REFRERENCIAS BIBLIOGRÁFICAS}

1. Buitrago AJ, Portela CR, Eusse GS. Grano de soya en alimentación de cerdos y aves. Asociación Americana de Soya; 1992.

2. Yoshisawa T. General view on Mycotoxins. Mycotoxin Inspection in food traiding course. Japan International Cooperation Agency JICA; 1998.

3. Mallmann CA, Dilkin P, Giacomini LZ, Rauber RH, Pereira CE. Micotoxinas en Ingredientes para Alimento Balanceado de Aves. XX Congreso Latinoamericano; Porto Alegre 25 - 28 del 2007. Brasil.

4. Bennett J, Klich M. Mycotoxins. Clin. Microbiol. Rev. 2003; 16 (3): 497 - 516.

5. Sharma R. Immunotoxicity of mycotoxins. J. Dairy Sci. 1993; 76: $892-897$.

6. Ross R K, Yuan JM, Yu MC, Wogan GN, Qian GS, Tu JT, Groopman J, Gao Y T, Henderson BE. Urinary aflatoxin biomarkers and risk of hepatocellular carcinoma. Lancet. 1992; 339:1413-1414.

7. Henry S H, Bosch FX, Bowers JC. Aflatoxin, hepatitis and worldwide liver cancer risks. 2002: 229-320. In DeVries JW, Trucksess MW, Jackson LS (ed.), Mycotoxins and food safety. Kluwer Academic/ Plenum Publications., New York.

8. Shotwell OL, Hesseltine CW, Burmeister HR, Kwolek WF, Shannon, GM, Hall HH. Survey of cereal grains and soybeans for the presence of aflatoxin. II. Corn and soybeans. Cereal Chemistry. 1969; 46: $454-463$.

9. Fernandez Pinto VE, Vaamonde G, Brizzio SB, Apro N. Aflatoxin production in soybean varieties grown in Argentina. Journal of Food Protection. 1991; 54: 542 - 545.

10. Song DK, Karr AL. Soybean phytoalexin, glyceollin, prevents accumulation of aflatoxin B1 in cultures of Aspergillus flavus. Journal of Chemical Ecology. 1993; 19: 1183 1194.

11. Jay J. Modern food microbiology. 6a ed. Aspen Publication; 2000. 679 p.

12. Leeson S, Diaz GJ, Summers JD. Poultry metabolic disorders and mycotoxins. University Books, Guelph, Ontario, Canada. 1995: 227-241.

13. Castro J, Alvarado A, Koga Y, Tinoco R. Cuantificación de micotoxinas en ingredientes alimenticios utilizados en la dieta de aves comerciales. Rev Inv Vet Perú. 2015; 26(4): $558-564$.

14. Soriano del Castillo, José Migue. Micotoxinas en alimentos. Ediciones Díaz de Santos; 2007. ISBN 9788479788087.

15. Gimeno Alberto. Revisión de las concentraciones máximas tolerables para ciertas micotoxinas en animales. Consultor técnico de SPECIAL NUTRIENTS, INC., 2766 Douglas Road, Miami, Florida, 33133 USA; 2010. 